\title{
Case Report \\ Excision of Mucocele Using Diode Laser in Lower Lip
}

\author{
Subramaniam Ramkumar, ${ }^{1}$ Lakshmi Ramkumar, ${ }^{2}$ \\ Narasimhan Malathi, ${ }^{3}$ and Ramalingam Suganya ${ }^{3}$ \\ ${ }^{1}$ Department of Oral \& Maxillofacial Surgery, Faculty of Dental Sciences, Sri Ramachandra University, Chennai, India \\ ${ }^{2}$ Dr. Ram's Dental Care \& Maxillofacial Center, Chennai, India \\ ${ }^{3}$ Department of Oral Pathology and Microbiology, Faculty of Dental Sciences, Sri Ramachandra University, Chennai, India
}

Correspondence should be addressed to Ramalingam Suganya; drsuganyapavendhan@yahoo.com

Received 26 July 2016; Revised 15 November 2016; Accepted 4 December 2016

Academic Editor: Tommaso Lombardi

Copyright (C) 2016 Subramaniam Ramkumar et al. This is an open access article distributed under the Creative Commons Attribution License, which permits unrestricted use, distribution, and reproduction in any medium, provided the original work is properly cited.

Mucoceles are nonneoplastic cystic lesions of major and minor salivary glands which result from the accumulation of mucus. These lesions are most commonly seen in children. Though usually these lesions can be treated by local surgical excision, in our case, to avoid intraoperative surgical complications like bleeding and edema and to enable better healing, excision was done using a diode laser in the wavelength of $940 \mathrm{~nm}$.

\section{Introduction}

Mucoceles are known as "mucus filled cavities" usually present in the oral cavity, lacrimal sac, and paranasal sinuses [1]. Mucus extravasation and mucus retention are the two most frequently occurring primary mechanical obstructive diseases of salivary glands [2]. Formation of mucus extravasation cyst is mainly due to mechanical trauma causing rupture of ductal system of salivary gland and mucin spills into adjacent soft tissues $[3,4]$. Mucus retention cyst is formed markedly by obstruction of salivary ductal walls causing dilatation of ducts without spillage of mucin $[5,6]$.

\section{Case Report}

A 16-year-old female presented with a swelling in the lower left labial mucosal region for the past few months. She complained of intermittent swelling which often bursts and disappears for a few days. On clinical examination, lesion was soft, painless, fluid-filled, and approximately $1 \times 1 \mathrm{~cm}$ in size (Figure 1). The history and clinical presentations were consistent with mucocele. Various treatment modalities such as surgical incision, cauterization, and laser excision were explained to the patient's guardian and obtained willingness to perform the most recent treatment option of laser excision.
Following minimal infiltration of $1: 2,00,000$ Xylocaine, the lesion was excised using soft diode laser in wavelength of $940 \mathrm{~nm}, 400 \mu \mathrm{m}$ diameter tip at $1.5 \mathrm{~W}$ in continuous mode. The incision was placed on the uppermost site of the lesion and complete excision was performed (Figures 2, 3(a), and 3(b)). The specimen (Figure 4) was subjected to histopathological examination and showed cystic cavity lined by thick fibrous capsule. Cystic lumen contains mucin, foamy macrophages, and chronic inflammatory cells. Areas of coagulation necrosis surrounding the intended biopsy material were also evident. Adjacent mucous salivary gland was also seen. With all these histopathological features, diagnosis of mucous extravasation cyst was given (Figures 5 and 6). Patient was prescribed analgesics. There was uneventful healing on 45 days of follow-up (Figures 7, 8, 9, 10, and 11).

\section{Discussion}

Mucocele is the second most common lesion in the oral cavity followed by irritational fibroma. Incidence of this lesion occurs in the age group between 10 and 29 years with equal gender distribution [7]. Mucoceles appear as dome-shaped mucosal swellings with the characteristic accumulation of 


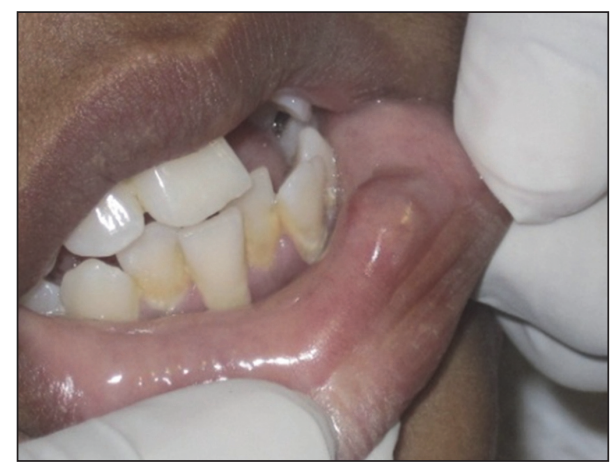

FIgURE 1: Swelling in the left labial mucosal region.

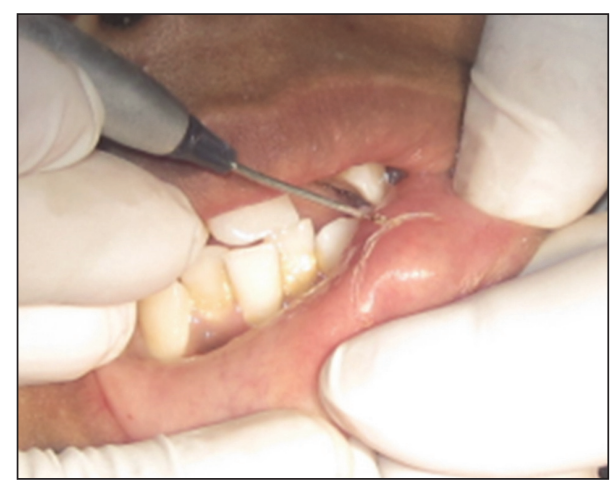

FIGURE 2: Application of laser: parameters, $940 \mathrm{~nm}$ and $1.5 \mathrm{~W}$; continuous mode, 400 microns.

mucin. These lesions usually impart bluish, transparent hue of variable size from 1-2 $\mathrm{mm}$ to several centimetres in dimension $[3,8]$. Lower lip is the most common site of occurrence of mucocele followed by the buccal mucosa and floor of mouth [9]. Depending upon the size and location of mucoceles, the various clinical features include external swelling and interference with mastication, swallowing, and speech and discomfort might occur [7]. Histopathologic examination of mucocele often reveals formation of well-circumscribed, cyst-like space surrounded by granulation tissue and the presence of mucinophages in the collapsed wall of granulation tissue [10]. The adjacent salivary gland tissue should also be present because mucocele should always be removed along with feeder glands/ducts which minimize recurrence of the lesion.

There are various treatment aspects available for the management of mucocele early: scalpel incision, complete surgical excision, marsupialization, micromarsupialization, intralesional injections of corticosteroids, cryosurgery, laser ablation, sclerosing agent, and electrocautery methods [8].

The main advantages of soft tissue laser applications are minimal intraoperative bleeding and swelling and postoperative pain and very less surgical time, scarring, and coagulation, without any need of suturing after excision because of natural wound dressing due to denatured proteins. Various procedures like minor and major soft tissue surgery, bone cutting, and implant exposure with bone removal can be

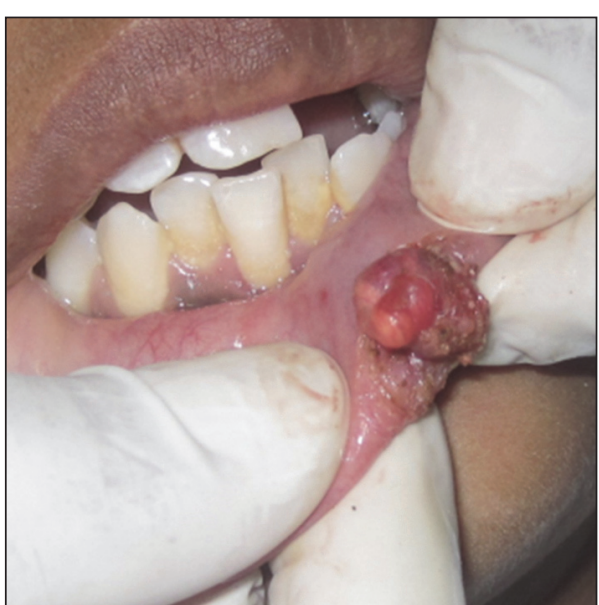

(a)

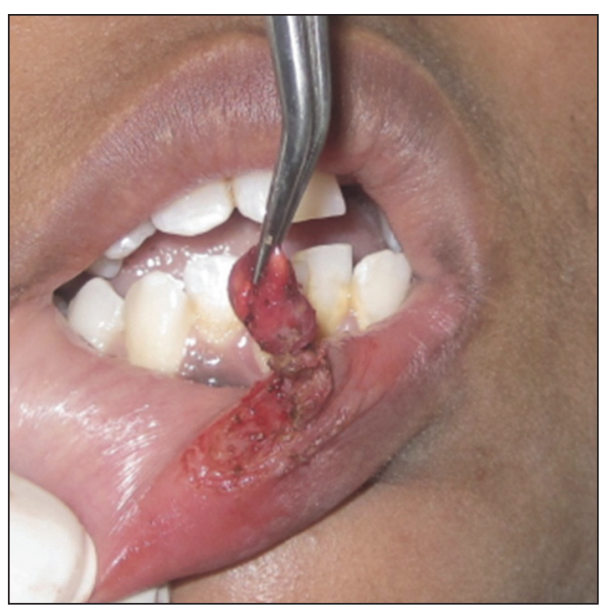

(b)

FIGURE 3: Intraoperative photograph.

performed in patients with bleeding disorders by using soft tissue lasers [11, 12].

The semiconductor diode lasers are available in different wavelengths such as $810-830 \mathrm{~nm}, 940 \mathrm{~nm}$, and $980 \mathrm{~nm}$ [13]. The present case was performed by using $940 \mathrm{~nm}$ in which excellent hemostasis can be achieved due to good affinity for pigments like haemoglobin [14].

Diode lasers can be a useful alternative to larger surgical lasers such Er:YAG and CO2 lasers. Their small size and low cost are distinct advantages. They can give a well-defined cutting edge, as well as coagulation and hemostasis during excisions [12].

Absorption of laser energy into the target tissue releases heat by photothermal process which further causes intraand extracellular vaporization of cells with resultant cellular explosion and tissue ablation. Adjacent lateral tissues will also absorb heat, on enough time of laser application. This will occur in concentric serial circles around the homogeneous target tissue. Reversible or irreversible damage of areas surrounding the target tissue by the thermal effects of laser results in zone of coagulation necrosis. Delayed healing and 


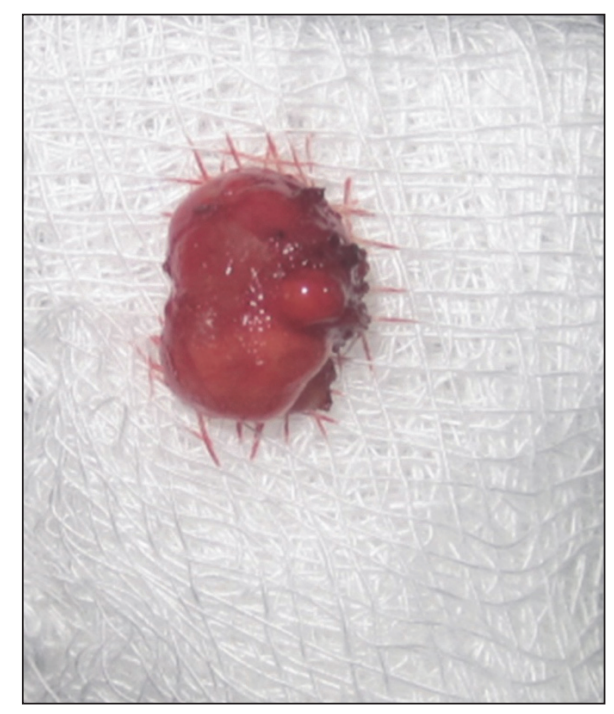

FIgURE 4: Excised specimen.

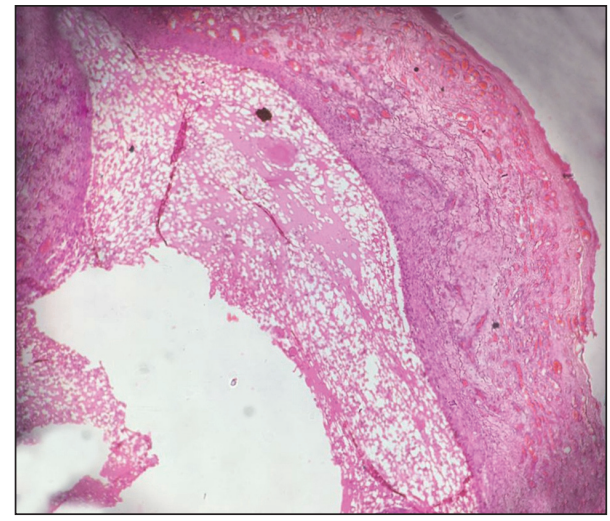

FIGURE 5: Photomicrograph showing H\&E 40x view cystic cavity lined by thick fibrous capsule. Cystic lumen contains mucin, foamy macrophages, and chronic inflammatory cells.

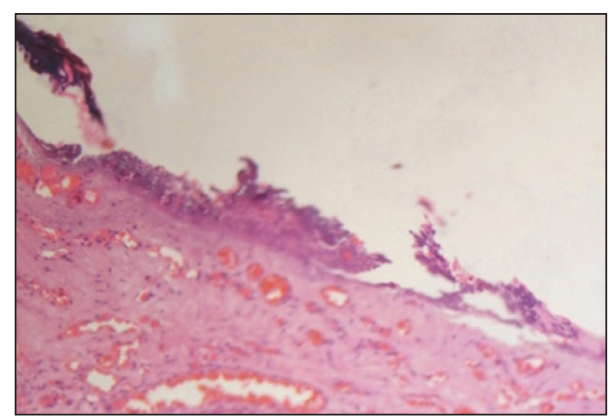

FIgURE 6: Photomicrograph showing H\&E 40x view zone of coagulation necrosis surrounding the intended biopsy material.

a larger wound site may occur on increased time of laser application. On the other hand, sealing of small diameter of vessels rather than the area of coagulation necrosis provides advantages like hemostasis during laser surgery. Area of adjacent coagulation ends with less bleeding at surgical site. The presence of border of necrotic and coagulated tissue in

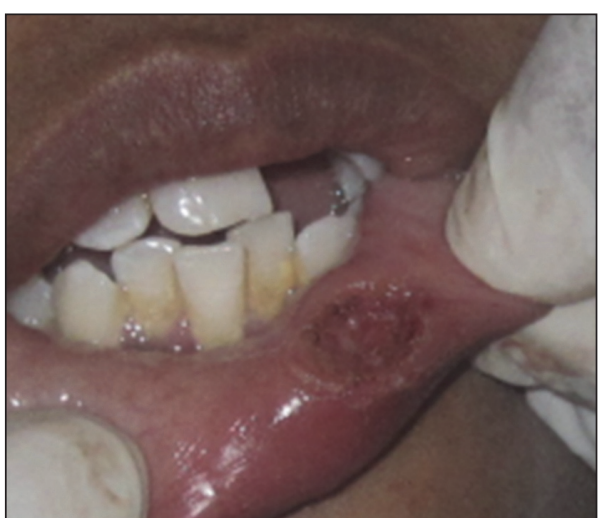

FIGURE 7: Photograph showing immediate postoperative day.

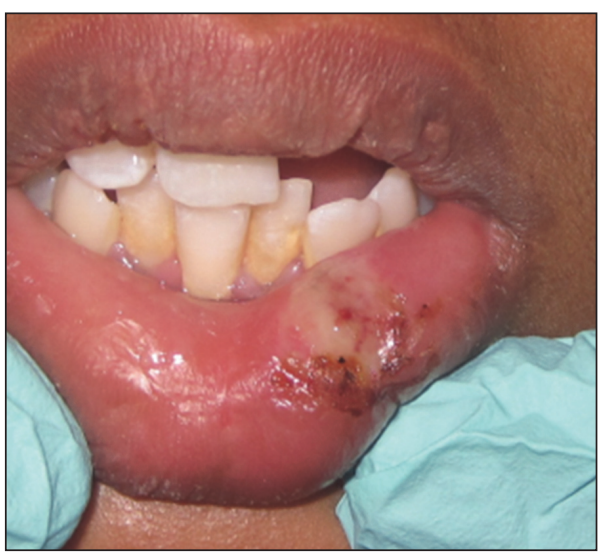

FIGURE 8: Photograph showing postoperative view: Day 1.

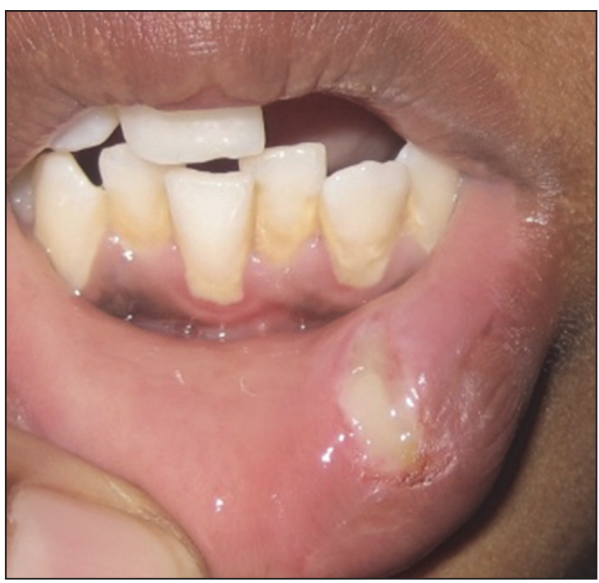

FIGURE 9: Photograph showing postoperative view: Day 4.

an incisional or excisional biopsy may result in intricacy of histopathological identification [15].

Histological examination of laser excised tissue shows improved epithelization and lesser inflammation. Intact basement membrane and connective tissue matrix can also be observed. Matrix proteins initiate reparative synthesis on these tissues. Resistance of matrix proteins against laser 


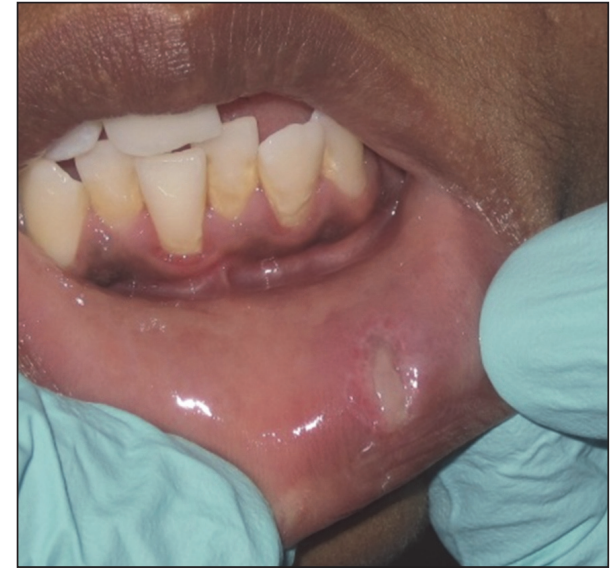

Figure 10: Photograph showing postoperative view: Day 8.

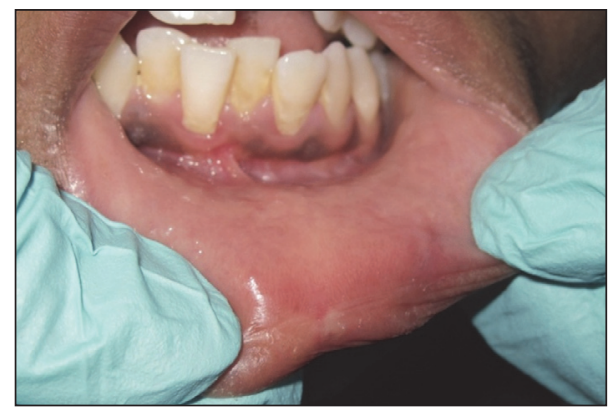

FIGURE 11: Photograph showing postoperative view: Day 45.

application and replacement as well as removal of residual matrix is responsible for reduced scarring and contraction [16].

\section{Conclusion}

Our present case report reveals knowledge about using diode laser for the treatment of mucocele with a variety of beneficial effects such as minimal anesthesia, less procedural timings, good surgical site visualization, hemostasis, and minimal carbonization in 45 days of periodical follow-up. Laser application makes it possible to reduce apprehension and fear in pediatric and geriatric patients.

\section{Competing Interests}

The authors declare that there is no conflict of interests regarding the publication of this paper.

\section{References}

[1] A. Qafmolla, M. Bardhoshi, N. Gutknecht, and E. Bardhoshi, "Evaluation of early and long term results of the treatment of mucocele of the lip using $980 \mathrm{~nm}$ diode laser " European Scientific Journal, vol. 10, no. 6, 2014.

[2] G. L. Ellis, P. L. Auclair, and D. R. Gnepp, Surgical Pathology of the Salivary Glands, Saunders, Philadelphia, Pa, USA, 1991.
[3] B. W. Neville, D. D. Damm, M. Allen, and J. E. Bouqot, Eds., Oral and Maxillofacial Pathology, Saunders, Philadelphia, Pa, USA, 2nd edition, 2002.

[4] N. Madan, "Excision of mucocele: a surgical case report," Biological and Biomedical Reports, vol. 2, no. 2, 2012.

[5] J. Ata-Ali, C. Carrillo, C. Bonet, J. Balaguer, M. Peñarrocha Diago, and M. Peñarrocha, "Oral mucocele: review of the literature," Journal of Clinical and Experimental Dentistry, vol. 2, no. 1, pp. e18-e21, 2010.

[6] M. Shear and P. Speight, Cyst of the Oral and Maxillofacial Region, Blackwell Munksgaard, New York, NY, USA, 4th edition, 2007.

[7] D. Re Cecconi, A. Achilli, M. Tarozzi et al., "Mucoceles of the oral cavity: a large case series (1994-2008) and a literature review," Medicina Oral, Patologia Oral y Cirugia Bucal, vol. 15, no. 4, pp. e551-e556, 2010.

[8] J. Yagüe-García, A.-J. España-Tost, L. Berini-Aytés, and C. GayEscoda, "Treatment of oral mucocele-scalpel versus CO2 laser," Medicina Oral, Patologia Oral y Cirugia Bucal, vol. 14, no. 9, pp. e469-e474, 2009.

[9] K. Chawla, A. K. Lamba, F. Faraz, S. Tandon, S. Arora, and M. Gupta, "Treatment of lower lip mucocele with Er, Cr: YSGG laser-a case report," The Journal of Oral Laser Applications, vol. 10, no. 4, pp. 181-185, 2010.

[10] E. Lee, S. H. Cho, and C. J. Park, "Clinical and immunehistochemical characteristics of mucoceles," Annals of Dermatology, vol. 21, no. 4, pp. 345-351, 2009.

[11] L. J. Walsh, "The current status of laser applications in dentistry," Australian Dental Journal, vol. 48, no. 3, pp. 146-155, 2003.

[12] E. Azma and N. Safavi, "Diode laser application in soft tissue oral surgery," Journal of Lasers in Medical Sciences, vol. 4, no. 4, pp. 206-211, 2013.

[13] A. C. Robert, Principles and Practice of Laser Dentistry, Mosby Elsevier, Maryland Heights, Mo, USA, 2010.

[14] G. Agarwal, A. Mehra, and A. Agarwal, "Laser vaporization of extravasation type of mucocele of the lower lip with $940-\mathrm{nm}$ diode laser," Indian Journal of Dental Research, vol. 24, no. 2, p. 278, 2013.

[15] G. A. Catone, C. C. Ailing, and B. M. Smith, "Laser Applications in Oral and Maxillofacial Surgery," Implant Dentistry, vol. 6, no. 3, p. 238, 1997.

[16] M. Luomanen, J. H. Meurman, and V. P. Lehto, "Extracellular matrix in healing $\mathrm{CO}_{2}$ laser incision wound," Journal of Oral Pathology \& Medicine, vol. 16, no. 6, pp. 322-331, 1987. 


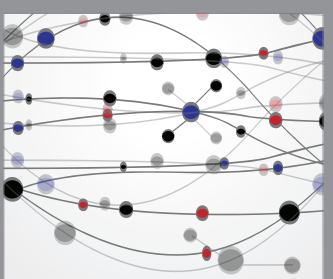

The Scientific World Journal
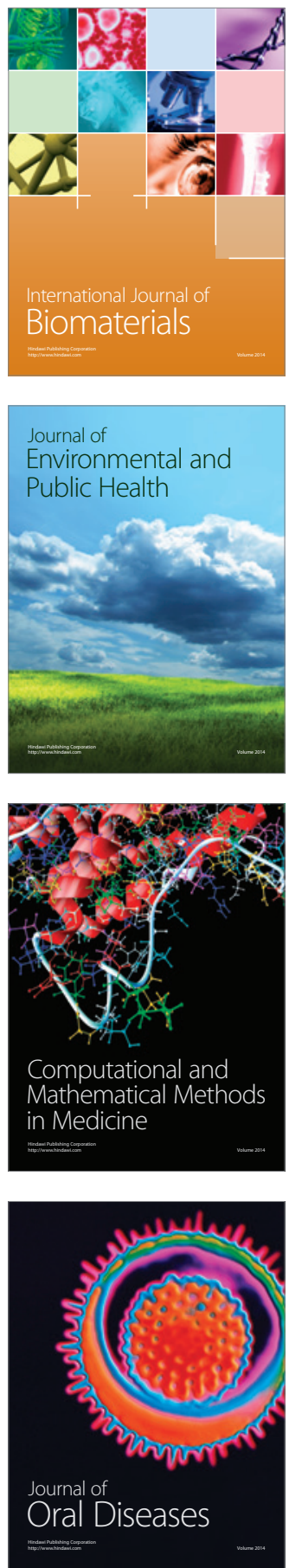
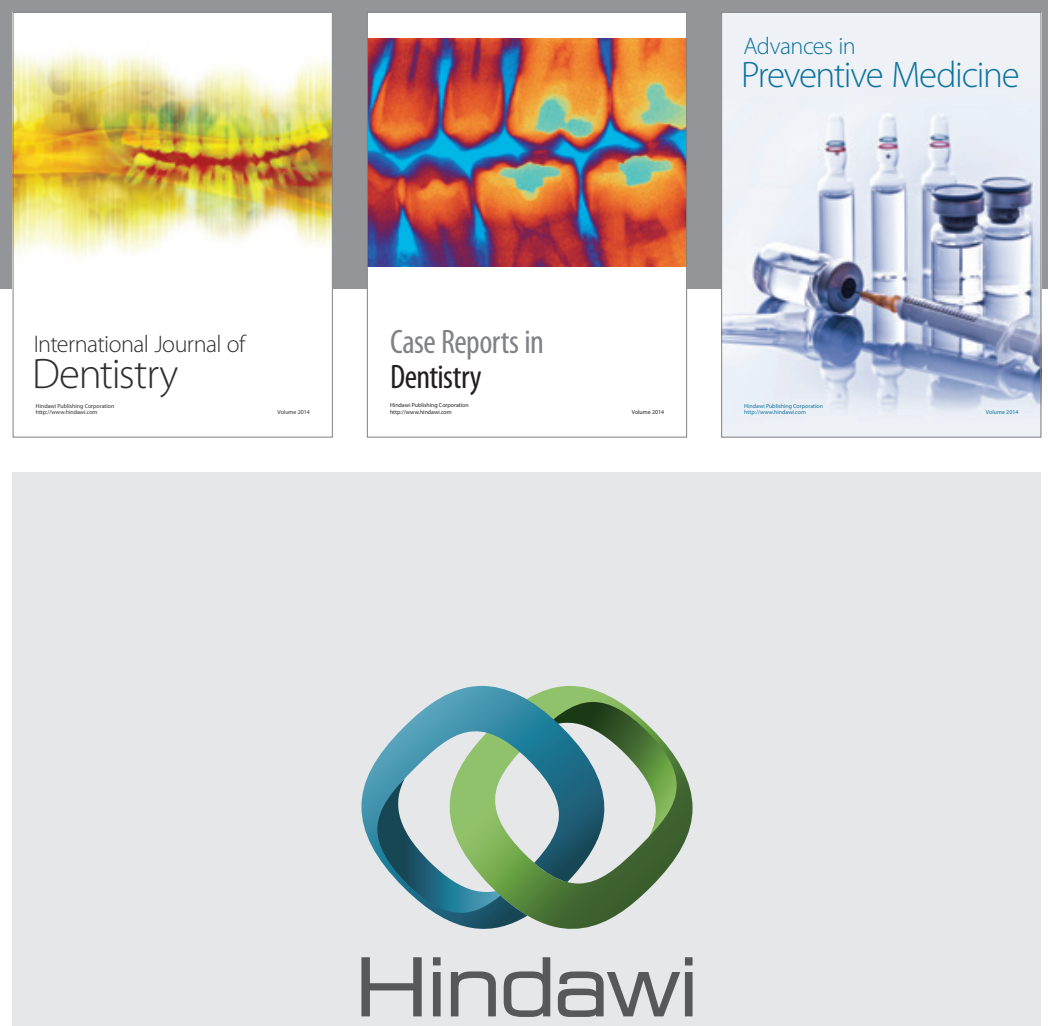

Submit your manuscripts at

http://www.hindawi.com
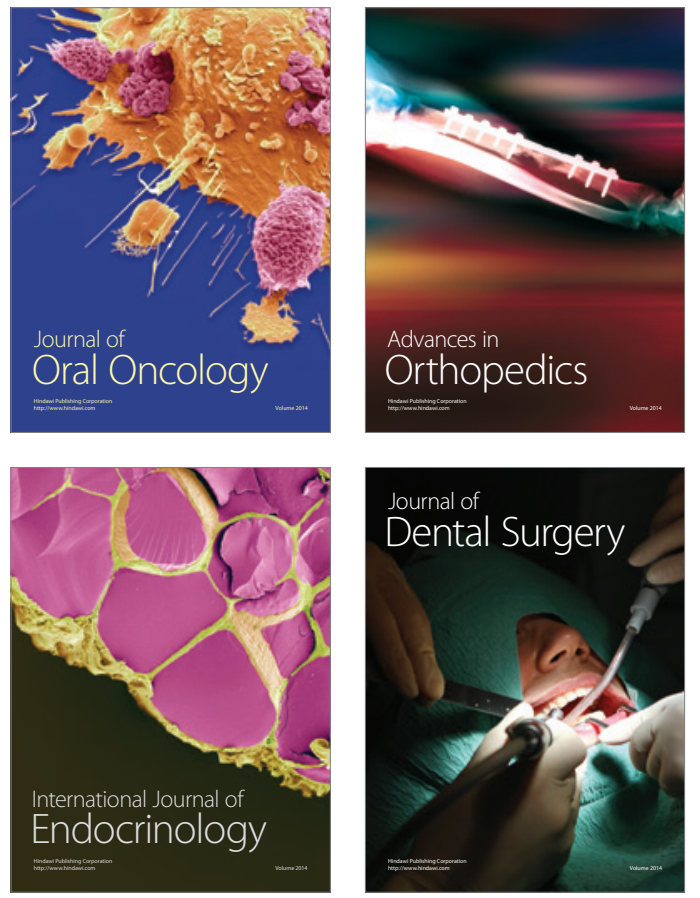
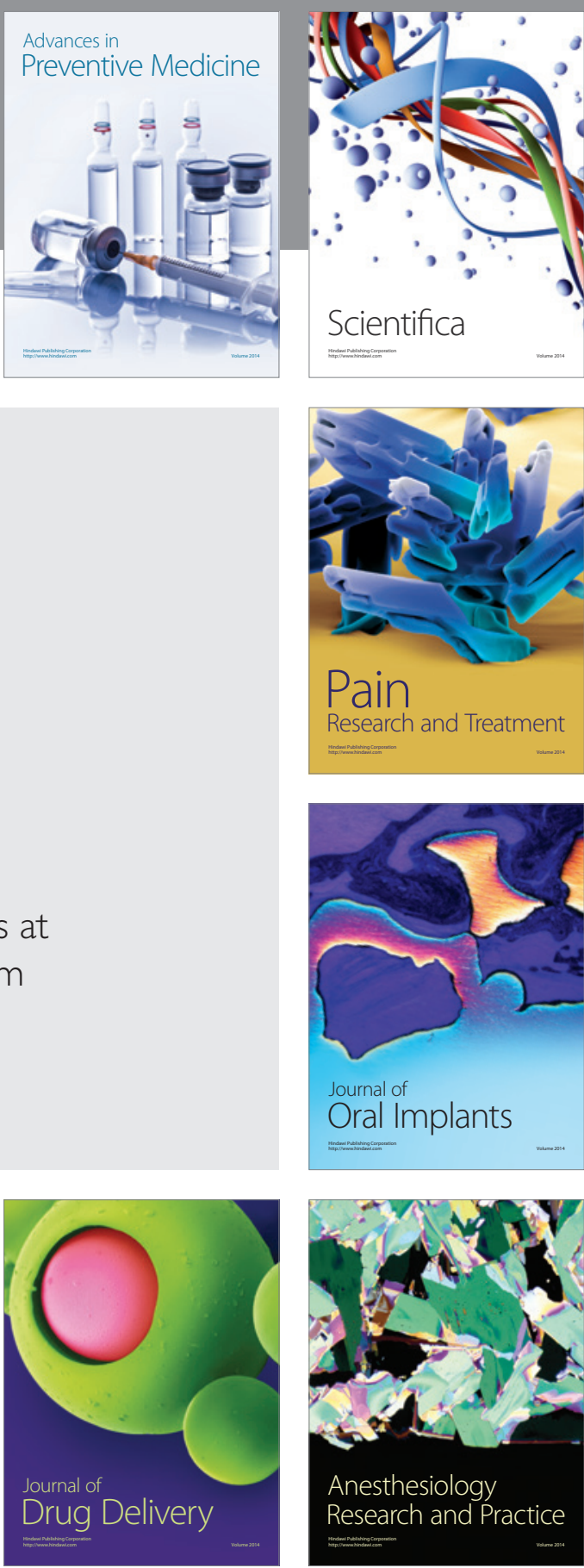

Scientifica
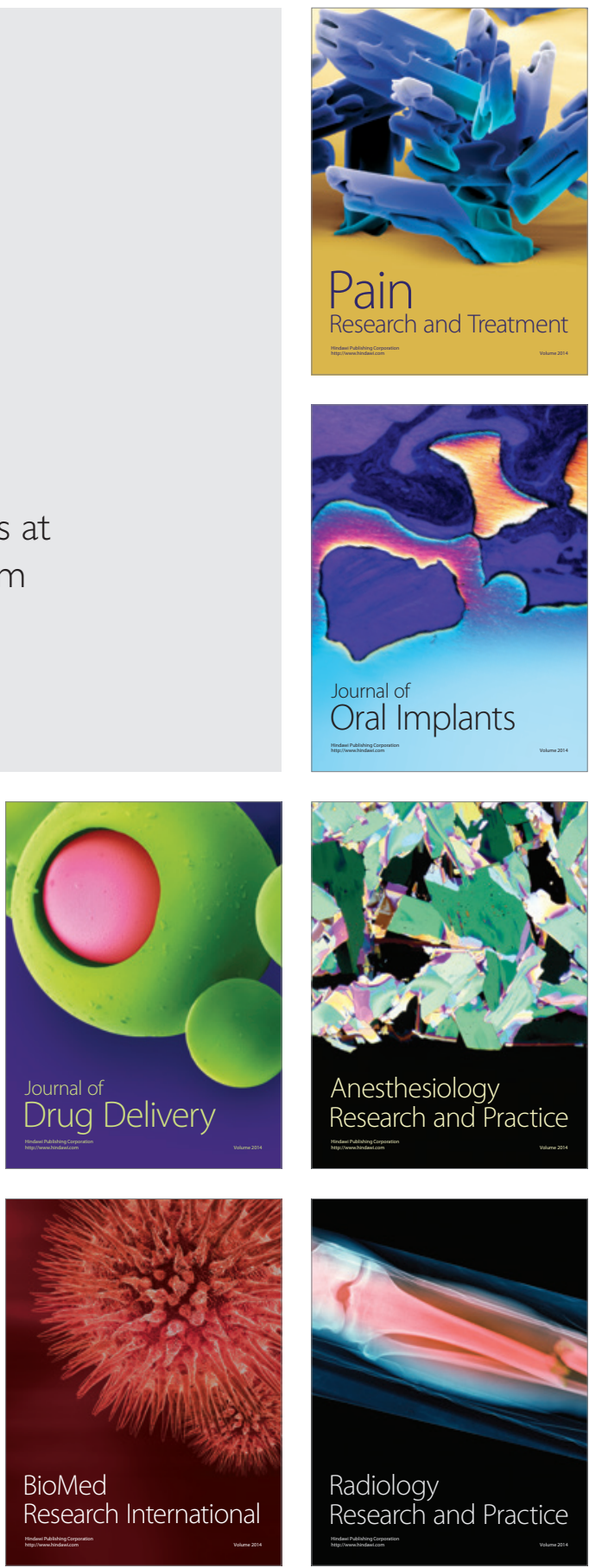